\title{
Polysulfone/Clay Nanocomposites by in situ Photoinduced Crosslinking Polymerization
}

\author{
Cemil Dizman, Sahin Ates, Tamer Uyar, Mehmet Atilla Tasdelen,* \\ Lokman Torun,* Yusuf Yagci*
}

PSU/MMT nanocomposites are prepared by dispersing MMT nanolayers in a PSU matrix via in situ photoinduced crosslinking polymerization. Intercalated methacrylate-functionalized MMT and polysulfone dimethacrylate macromonomer are synthesized independently by esterification. In situ photoinduced crosslinking of the intercalated monomer and the PSU macromonomer in the silicate layers leads to nanocomposites that are formed by individually dispersing inorganic silica nanolayers in the polymer matrix. The morphology of the nanocomposites is investigated by XRD and TEM, which suggests the random dispersion of silicate layers in the PSU matrix. TGA results confirm that the thermal stability and char yield of PSU/MMT nanocomposites increases with the increase of clay loading.

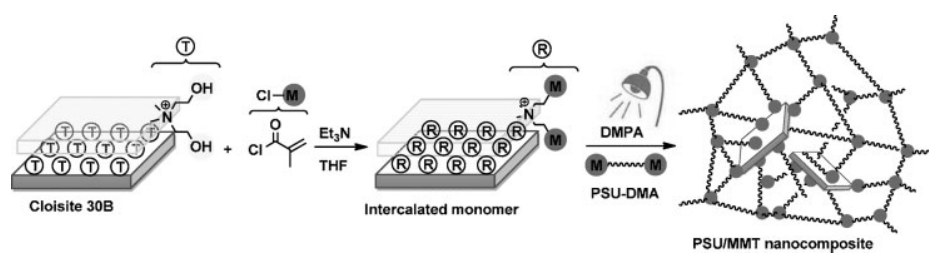

\section{Introduction}

Polysulfone (PSU) is a highly engineered thermoplastic with chemical resistance to hydrolysis, acids and bases and favorable high temperature properties. ${ }^{[1]}$ Due to these excellent properties, PSU can be used in medical devices, food processing, feeding systems, automotive, and electro-

C. Dizman, S. Ates, Dr. L. Torun

Chemistry Institute, TUBITAK Marmara Research Center, Gebze, Kocaeli 41470, Turkey

E-mail: lokman.torun@mam.gov.tr

C. Dizman, S. Ates, Prof. Y. Yagci

Department of Chemistry, Istanbul Technical University, Maslak, Istanbul 34469, Turkey

E-mail: yusuf@itu.edu.tr

T. Uyar

UNAM-Institute of Materials Science \& Nanotechnology, Bilkent University, 06800 Ankara, Turkey

Dr. M. A. Tasdelen

Department of Polymer Engineering, Faculty of Engineering,

Yalova University, TR-7710o Yalova, Turkey

E-mail: tasdelen@yalova.edu.tr nic industry. ${ }^{[2]}$ Depending on the area of application, PSU polymers are often modified to give materials with additional physical properties. ${ }^{[3]}$ Recently, our groups have focused on the functionalization of PSU either by end-group transformation with (meth)acrylate chloride through esterification or side chain modification with propargyl pyrene via click chemistry. ${ }^{[4]}$

Polymer-layered clay nanocomposites have gained much attention in industry and in academia because they exhibit significant improvements in materials properties such as thermal resistance, lower gas permeability, flame retardancy, solvent resistance, and mechanical properties compared to the neat polymer or micro- and macrocomposites. ${ }^{[5-7]}$ Because of the large surface area of nanosized clay layers interacting with the host polymer matrix, the choice of the convenient clay and/or the modification of the clay have gain importance. Montmorillonite (MMT) is the most commonly used layered silicates, due to it is ability to finetune their hydrophilic nature to hydrophobic through ion exchange reactions, which can enhance the compatibility of polymer with silicate layers. There are three methods for the preparation of polymer/clay nanocomposites: solution 
exfoliation, melt intercalation, and in situ polymerization. ${ }^{[6]}$ Latter is the best and mostly used way to prepare the nanocomposites because of the types of nanofillers and polymer precursors can be varied in a wide range to get the enhanced properties. ${ }^{[8]}$ In this method monomer, initiator, and/or catalyst are intercalated into silicate layers and the in situ polymerization is initiated by externally stimulation. ${ }^{\left[{ }^{9-11]}\right.}$ Polymerization within the clay galleries leads to the exfoliation of the layered silicate in the polymer matrix as well as the formation of polymer/clay nanocomposites. Various in situ polymerization techniques such as, conventional free radical polymerization, ${ }^{[12-16]}$ controlled radical polymerization, ${ }^{[17-23]}$ ring-opening polymerization, ${ }^{[24-30]}$ ring-opening metathesis polymerization, ${ }^{\text {[31-33] }}$ cationic polymerization, ${ }^{[34,35]}$ and anionic polymerization, ${ }^{[36,37]}$ have been widely used for the preparation of polymer/clay nanocomposites. Among them, free-radical polymerization is the most practical and simple method to prepare nanocomposites with wide range of monomers. Photoinitiated polymerization has several advantages compared to thermal polymerization, including low temperature conditions, solvent-free formulation and a rapid polymerization rate. ${ }^{[38-40]}$ It is applied to form polymer/clay nanocomposites with various types of polymers, such as polyacrylamide, ${ }^{[41]}$ polymethacrylates, ${ }^{[14,16,42-45]}$ poly(vinyl ether) and epoxides. ${ }^{[43,44,46,47]}$

In the literature, few papers about PSU/clay nanocomposites are presented. ${ }^{[48-52]}$ Although solution exfoliation has been used in all examples, in situ polymerization method has not been reported. In this work, we report an easy preparation of PSU/MMT nanocomposite by using in situ photoinduced crosslinking polymerization of PSU macromonomer and intercalated monomer. The crosslinking of the intercalated monomer and PSU dimethacrylate could gradually push the layers apart, leading to delamination of clay tactoids. Exfoliated silicate layers in the PSU/MMT nanocomposites have been analyzed by $\mathrm{X}$-ray diffraction (XRD), and transmission electron microscopy (TEM) and the effect of clay loading to the thermal properties is also studied by differential scanning calorimetry (DSC) and thermogravimetric analysis (TGA).

\section{Experimental Section}

\section{Materials}

PSU dimethacrylate macromonomer $\left(\bar{M}_{\mathrm{n}}=2100 \mathrm{~g} \cdot \mathrm{mol}^{-1}\right)$ was synthesized by condensation polymerization of bisphenol A and bis( $p$-chlorophenyl)sulfone and subsequent esterification with methacryloyl chloride according to the published method. ${ }^{[53]}$ Organo-modified clay, Cloisite 30B [MMT- $\left.\left(\mathrm{CH}_{2} \mathrm{CH}_{2} \mathrm{OH}\right)_{2}\right]$ was purchased from Southern Clay Products (Gonzales, TX, USA). The clay is a MMT modified by methylbis(2-hydroxyethyl)(tallow alkyl)ammonium ions. The organic content of the organo-modified
MMT, determined by TGA, was $21 \mathrm{wt} \%$. Before use, the clay was dried under vacuum at $110^{\circ} \mathrm{C}$ for $1 \mathrm{~h}$. Tetrahydrofuran (THF, $+99 \%$, Fluka) was dried over sodium metals and distilled over just before use. Bisphenol A and bis(p-chlorophenyl)sulfone (Hallochem Pharma Co. Ltd, China), methanol (Merck), dimethylacetamide (DMAC, 99\%, Merck), and triethylamine (TEA, Aldrich, HPLC grade) were used without any purification. Dichloromethane (99\%, Aldrich), chloroform (+99\%, Aldrich), methacryloyl chloride (+97\%, Merck) were used as received. 2.2-Dimethoxy-2-phenylacetophenone (DMPA, 99\%, Acros) was also used without any additional treatment.

\section{Modification of MMT with Methacryloyl Chloride}

Methylbis(2-hydroxyethyl)(tallow alkyl)ammonium organomodified clay [MMT- $\left(\mathrm{CH}_{2} \mathrm{CH}_{2} \mathrm{OH}\right)_{2}, 2.25 \mathrm{~g}, 2.75 \mathrm{mmol}$, OH content] and TEA (1.85 mL, $13.25 \mathrm{mmol}$ ) were added in THF $(50 \mathrm{~mL})$ and cooled to $0{ }^{\circ} \mathrm{C}$. Methacryloyl chloride $(1.1 \mathrm{~mL}, 13.3 \mathrm{mmol})$ was added dropwise while stirring. The reaction mixture was allowed to heat up to room temperature and stirred overnight. After cooling to room temperature and removing the solvent by rotary evaporation, ether $(200 \mathrm{~mL})$ was added to the crude reaction mixture and washed three times with a saturated $\mathrm{NaCl}$ aqueous solution. The clay was then filtered off on a cold silica filter, washed with water, and finally dried in vacuum.

IR (ATR): $v=3612(-\mathrm{OH}), 3380(-\mathrm{NR}), 2965\left(-\mathrm{CH}_{3}\right.$ sym), $2872\left(-\mathrm{CH}_{2}\right.$ sym), $1724(-\mathrm{C}=\mathrm{O}), 1625(-\mathrm{C}=\mathrm{C}-)$, and 1210 (C-O-C) $\mathrm{cm}^{-1}$.

\section{Preparation of the PSU/MMT Nanocomposites}

The organomodified clay (1, 3, and 5 wt\% monomer) and DMPA (1 wt\% oligomer) was mixed with PSU-DMA oligomer dissolved in dry $\mathrm{CH}_{2} \mathrm{Cl}_{2}(2 \mathrm{~mL})$ in Pyrex tubes via a magnetic stirrer at room temperature for $12 \mathrm{~h}$ and degassed with nitrogen prior to irradiation by a merry-go-round type reactor equipped with 16 Philips 8W/06 lamps emitting light at $\lambda>350 \mathrm{~nm}$ and a cooling system. At the end of $4 \mathrm{~h}$, polymers were precipitated into methanol, filtered, dried, and weighed. Conversions, the percentage of the macromonomer converted into insoluble network were determined gravimetrically.

\section{Characterization}

Fourier-transform infrared (FT-IR) spectra were recorded on a Perkin-Elmer FT-IR Spectrum One B spectrometer. DSC was performed on a Perkin-Elmer Diamond DSC with a heating rate of $10^{\circ} \mathrm{C}$ min under nitrogen flow. TGA was performed on PerkinElmer Diamond TA/TGA with a heating rate of $10^{\circ} \mathrm{C}$ min under nitrogen flow. The powder XRD measurements were performed on a PANalytical X'Pert PRO X-ray diffractometer equipped with graphite-monochromatized $\mathrm{Cu} \mathrm{K}_{\alpha}$ radiation $(\lambda=1.15 \AA$ ). TEM imaging of the samples was carried out by FEI TecnaiTM G2 F30 instrument operating at an acceleration voltage of $200 \mathrm{kV}$. Each sample was dispersed in methanol and drop-cast onto carbon coated grid for the TEM imaging. 


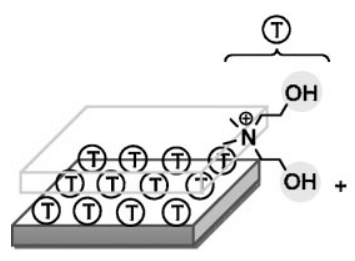

Cloisite 30B

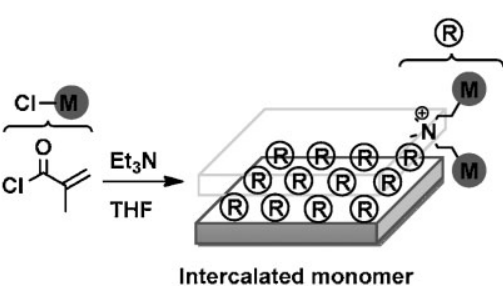

Intercalated monomer

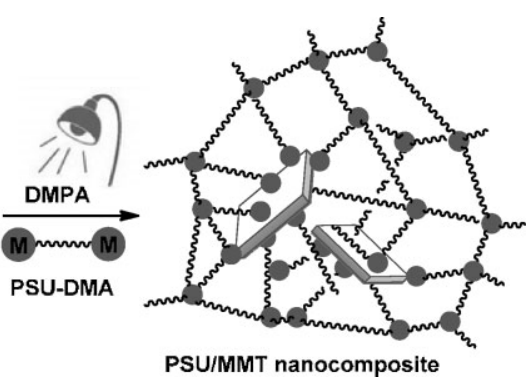

Scheme 1. Preparation of PSU/MMT clay nanocomposites by in situ photoinitiated crosslinking polymerization.

\section{Results and Discussion}

Intercalated methacrylate-functionalized montmorillonite (I-MMT) clay was prepared from commercial MMT clay containing two hydroxyl groups (Closite 30B) by using esterification reaction with methacryloyl chloride. The FTIR spectrum of resulting MMT clay showed that a characteristic carbonyl peak at $1730 \mathrm{~cm}^{-1}$ corresponding to methacrylate moiety, whereas a broad peak at around $3400 \mathrm{~cm}^{-1}$ indicates that small amount of nonfunctionalized hydroxy groups on the surface of the layers is still remained. The PSU dimethacrylate (PSU-DMA) macromonomer was synthesized by condensation polymerization between bisphenol A and bis( $p$-chlorophenyl)sulfone, and subsequent esterification process. First, the precursor diolfunctionalized PSU was obtained by condensation polymerization adjusting monomer concentration to yield oligomer possessing phenolic groups at both ends. Then, this oligomer was reacted with methacryloyl chloride in the presence of $\mathrm{Et}_{3} \mathrm{~N}$ as the base to give desired PSU-DMA.

Polysulfone/montmorillonite (PSU/MMT) nanocomposites were prepared by in situ photoinitiated crosslinking polymerization of I-MMT and PSU-DMA monomers. Photo- chemically generated radicals can allow polymer molecules to grow inside the clay galleries upon irradiation and consequently form covalent bonds between organic and inorganic phases. Attachment of monomeric sites into clay layers and subsequent photoinduced crosslinking of immersed monomers with PSU-DMA macromonomers facilitate propagation and exfoliation processes concomitantly, leading to the formation of homogeneous clay/ polymer nanocomposites (Scheme 1). The characteristic data for I-MMT, PSU-DMA, and PSU/MMT nanocomposites synthesized with different clay loadings were given in Table 1.

XRD curves of the intercalated MMT and PSU nanocomposites are illustrated in Figure 1. According to the XRD diffraction pattern, changes in the value of $2 \theta$ reflect changes in the gallery distance of the clay. The organomodified clay sample exhibits a peak at 4.95, which corresponds to a basal space $\left(d_{001}\right)$ of $1.80 \mathrm{~nm}$. As can be seen in Figure 1, after the polymerization, it is completely disappeared in all nanocomposite samples. Although, these results indicate that the silicate layers are likely to be exfoliated in the matrix, XRD measurements alone are not conclusive for determining the true structures and dis-

Table 1. Photoinitiated crosslinking polymerizationof PSU-DMA in the presence and absence of organomodified I-MMT, and thermal properties of neat PSU, I-MMT, and resulting nanocomposites.

\begin{tabular}{|c|c|c|c|c|c|c|c|}
\hline \multirow[t]{2}{*}{ Sample } & \multirow[t]{2}{*}{$\begin{array}{l}\text { MMT } \\
\text { [wt\%] }\end{array}$} & \multirow[t]{2}{*}{$\begin{array}{c}\text { Conv. }{ }^{a)} \\
{[\%]}\end{array}$} & \multirow[t]{2}{*}{$\begin{array}{l}\left.d_{001}{ }^{b}\right) \\
{[n m]}\end{array}$} & \multirow[t]{2}{*}{$\begin{array}{l}T_{\mathrm{g}}^{\mathrm{c})} \\
{\left[{ }^{\circ} \mathrm{C}\right]}\end{array}$} & \multicolumn{2}{|c|}{$\begin{array}{c}\text { Weight loss } \\
\text { temperature }{ }^{\mathrm{d})} \\
{\left[{ }^{\circ} \mathrm{C}\right]}\end{array}$} & \multirow[t]{2}{*}{$\begin{array}{c}\text { Char } \\
\text { yield }^{\text {e) }} \\
{[\%]}\end{array}$} \\
\hline & & & & & $20 \mathrm{wt} \%$ & $60 \mathrm{wt} \%$ & \\
\hline I-MMT & - & 80 & 1.8 & - & 726.3 & - & 78.6 \\
\hline PSU-DMA ${ }^{\mathrm{e})}$ & - & 67 & - & 136.7 & 456.1 & 526.2 & 21.2 \\
\hline $\mathrm{NC}^{\mathrm{e})}$ & 1 & 81 & - & 146.3 & 467.1 & 530.1 & 24.1 \\
\hline $\mathrm{NC}^{\mathrm{e})}$ & 3 & 85 & - & 144.4 & 484.0 & 536.9 & 30.0 \\
\hline $\left.\mathrm{NC}^{\mathrm{e}}\right)$ & 5 & 75 & - & 143.1 & 497.1 & 551.3 & 34.1 \\
\hline
\end{tabular}

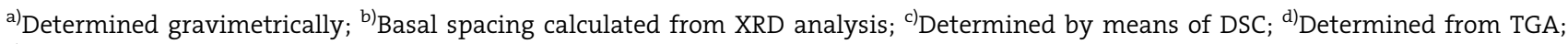
e) $[$ photoinitiator] $=1 \mathrm{wt} \%$ of monomer.

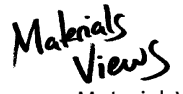

www.MaterialsViews.com
Macromol. Mater. Eng. 2011, 296, 1101-1106

(c) 2011 WILEY-VCH Verlag GmbH \& Co. KGaA, Weinheim 


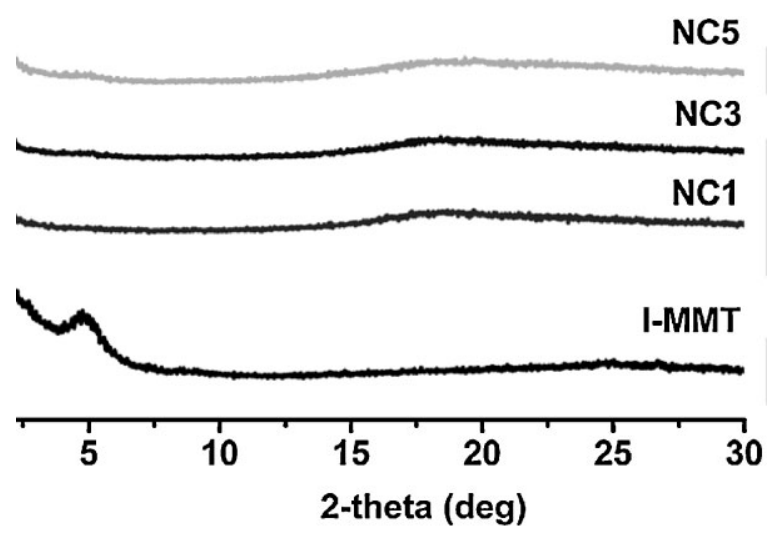

Figure 1. XRD analysis of organo-modified clay I-MMT, $\mathrm{NC}_{1}, \mathrm{NC}_{3}$, and $\mathrm{NC}_{5}$ nanocomposites.

tributions of the silica platelets; thus, we turned our attention to by TEM measurements.

A direct evidence for the nanocomposite formation is obtained TEM observation with two different magnification scales as displayed in Figure 2 for NC1, NC3, and NC5 samples. In the powdery PSU/MMT nanocomposites, the dark line represents individual silicate layers, whereas the brighter area represents the PSU matrix. In the both magnifications, TEM analysis indicates that all nanocomposites have a mixed morphology. The observed individual clay layers [highlighted by black arrows (e)] are well dispersed (delaminated) in the polymer matrix. In addition,

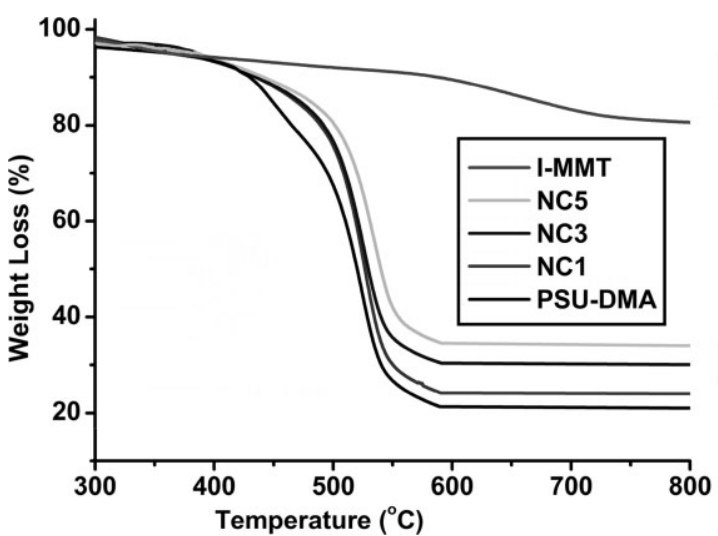

Figure 3. TGA thermograms of neat PSU-DMA, organo-modified clay I-MMT, $\mathrm{NC}_{1}, \mathrm{NC}_{3}$, and $\mathrm{NC}_{5}$ nanocomposites.

large intercalated tactoids [highlighted by black arrows (i)] can also be visible in the all samples. The small stacks of intercalated structure may be described as the incomplete activation of intercalated MMT monomer in the polymerization due to the high loading degree or limited mobility of PSU macromonomer within the layers. TEM analysis also confirms that the concentration of clay in the nanocomposites increased with increasing clay loading in the process (Figure 2).

TGA thermograms of neat PSU/DMA and its nanocomposites are shown in Figure 3. It is quite obvious that the decomposition temperatures of the nanocomposites are
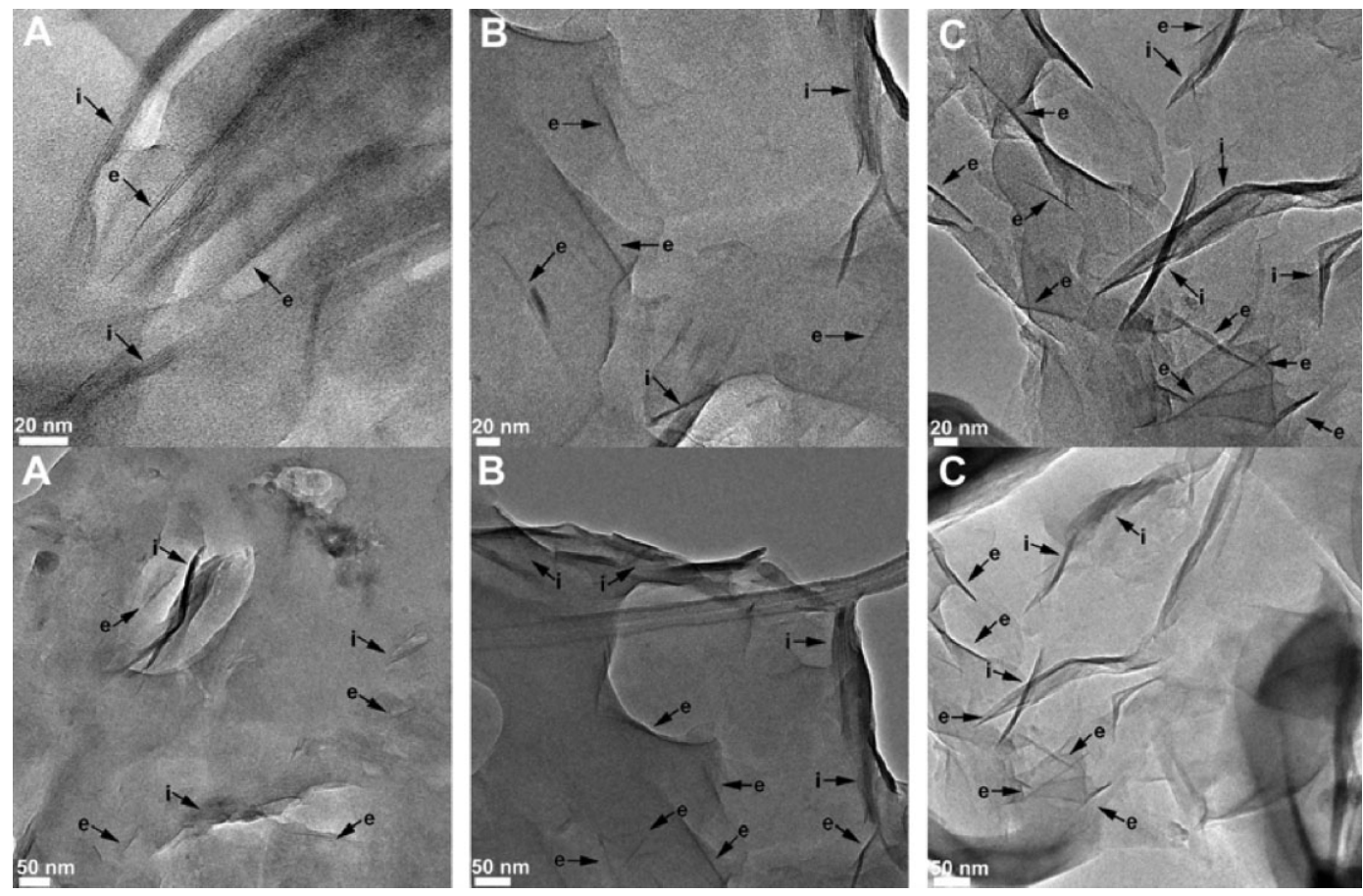

Figure 2. TEM micrographs of PSU/MMT nanocomposites ( $\left.\mathrm{A}, \mathrm{NC} \mathrm{C}_{1}\right),\left(\mathrm{B}, \mathrm{NC} \mathrm{C}_{3}\right)$, and $\left(\mathrm{C}, \mathrm{NC} \mathrm{C}_{5}\right)$ in high (scale bar: $20 \mathrm{~nm}$, upper images) and low magnification (scale bar: $50 \mathrm{~nm}$ ). 


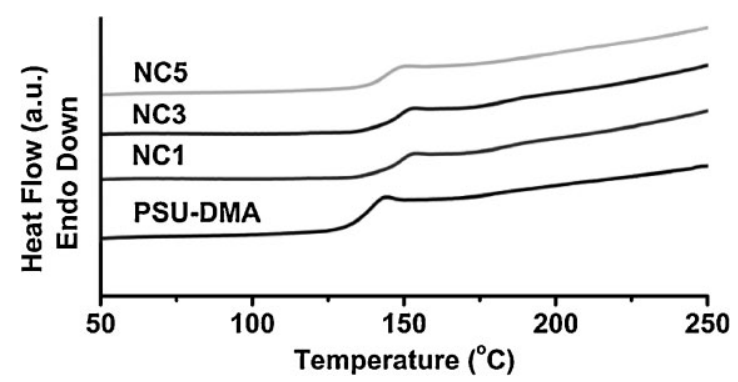

Figure 4. DSC traces of neat PSU-DMA, $\mathrm{NC}_{1}, \mathrm{NC}_{3}$, and $\mathrm{NC}_{5}$ nanocomposites.

higher than the neat oligomer. Notably, the final char yield of nanocomposites is increased with increasing organo-clay concentrations. Approximate decomposition temperatures of neat PSU-DMA and NC1, NC3, and NC5 were 485, 494, 496, and $504^{\circ} \mathrm{C}$, respectively. In the nanocomposites, the enhancement in the thermal stability could be explained by the barrier properties attributed to the clay mineral layers which hampered the diffusion of oxygen molecules into the nanocomposites and also the diffusion of the combustion products outside the system. The same trend was also observed by previous studies, which were prepared the PSU/MMT nanocomposites via a solution exfoliation method. ${ }^{[48,52]}$

DSC traces of neat PSU/DMA and corresponding nanocomposites are shown in Figure 4 . The $T_{\mathrm{g}}$ of polymers depends mainly on the molecular structure of the polymer (chain stiffness, number, and bulkiness of the side groups, and the inter- and intra/molecular interactions) and on the crosslink density of the polymer. ${ }^{[54-56]}$ All the nanocomposites show a higher $T_{\mathrm{g}}$ value compared to pure PSU. The highest increment in $T_{\mathrm{g}}$ of $\mathrm{NC1}$ nanocomposite can be ascribed to its exfoliation morphology with fine dispersion of silicate layers in the polymer matrix that provides large surface area for clay interacting with polymer matrix which can be lead to the restricted segmental motions near the organic/inorganic interfaces. ${ }^{[4,57]}$ Conclusively, with the increase of the clay content to PSU chains, leading to a slight decrease of $T_{\mathrm{g}}$.

\section{Conclusion}

In conclusion, PSU/MMT nanocomposites were prepared by in situ polymerization technique for the first time. Polymerization through the interlayer galleries of the clay was achieved by crosslinking of methacrylate functionalized MMT clay and PSU-DMA macromonomer. The random dispersion of silicate layers in the PSU matrix was confirmed by XRD and TEM measurements. Exfoliation/ intercalation structures were found to be related to the loading degree and limited mobility of macromonomer.
DSC and TGA analyses showed that the all nanocomposites have higher $T_{\mathrm{g}}$ value and thermal stabilities relative to that of the neat PSU.

Acknowledgements: The authors thank the State Planning Organization of Turkey (DPT) for financial support (Project no: 2005K120920).

Received: March 25, 2011; Revised: May 20, 2011; Published online: July 25, 2011; DOI: 10.1002/mame.201100114

Keywords: clays; montmorillonite; nanocomposites; photopolymerization; polysulfones

[1] F. Wang, M. Hickner, Y. S. Kim, T. A. Zawodzinski, J. E. McGrath, J. Membr. Sci. 2002, 197, 231.

[2] M. A. Hickner, H. Ghassemi, Y. S. Kim, B. R. Einsla, J. E. McGrath, Chem. Rev. 2004, 104, 4587.

[3] M. D. Guiver, G. P. Robertson, M. Yoshikawa, C. M. Tam, "Functionalized polysulfones: Methods for chemical modification and membrane applications", in Membrane Formation and Modification, (Eds. I. Pinnau, B. D. Freeman), Vol. 744, in ACS Symposium Series, American Chemical Society, Washington 2000, p. 137.

[4] H. Toiserkani, G. Yilmaz, Y. Yagci, L. Torun, Macromol. Chem. Phys. 2010, 211, 2389.

[5] S. S. Ray, M. Okamoto, Prog. Polym. Sci. 2003, 28, 1539.

[6] M. Okamoto, Mater. Sci. Technol. 2006, 22, 756.

[7] M. Alexandre, P. Dubois, Mater. Sci. Eng., R 2000, $28,1$.

[8] M. A. Tasdelen, J. Kreutzer, Y. Yagci, Macromol. Chem. Phys. 2010, 211, 279.

[9] J. Faucheu, C. Gauthier, L. Chazeau, J. Y. Cavaille, V. Mellon, E. B. Lami, Polymer 2010, 51, 6.

[10] J. Faucheu, C. Gauthier, L. Chazeau, J. Y. Cavaille, V. Mellon, F. Pardal, E. B. Lami, Polymer 2010, 51, 4462.

[11] Y. S. Ye, Y. C. Yen, C. C. Cheng, Y. J. Syu, Y. J. Huang, F. C. Chang, Polymer 2010, 51, 430.

[12] M. Okamoto, S. Morita, H. Taguchi, Y. H. Kim, T. Kotaka, H. Tateyama, Polymer 2000, 41, 3887.

[13] X. Fu, S. Qutubuddin, Polymer 2001, 42, 807.

[14] A. Nese, S. Sen, M. A. Tasdelen, N. Nugay, Y. Yagci, Macromol. Chem. Phys. 2006, 207, 820.

[15] H. Akat, M. A. Tasdelen, F. Du Prez, Y. Yagci, Eur. Polym. J. 2008, 44, 1949.

[16] A. Oral, M. A. Tasdelen, A. L. Demirel, Y. Yagci, Polymer 2009, 50, 3905.

[17] H. Bottcher, M. L. Hallensleben, S. Nuss, H. Wurm, J. Bauer, P. Behrens, J. Mater. Chem. 2002, 12, 1351.

[18] N. Salem, D. A. Shipp, Polymer 2004, 46, 8573.

[19] B. O. Zhang, C. Y. Pan, C. Y. Hong, B. Luan, P. J. Shi, Macromol. Rapid Commun. 2006, 27, 97.

[20] C. Konn, F. Morel, E. Beyou, P. Chaumont, E. Bourgeat-Lami, Macromolecules 2007, 40, 7464.

[21] P. Ding, M. Zhang, J. Gai, B. J. Ou, J. Mater. Chem. 2007, 17, 1117.

[22] Z. Yenice, M. A. Tasdelen, A. Oral, C. Guler, Y. Yagci, J. Polym. Sci., Part A: Polym. Chem. 2009, 47, 2190.

[23] R. E. Behling, B. A. Williams, B. L. Staade, L. M. Wolf, E. W. Cochran, Macromolecules 2009, 42, 1867.

[24] P. B. Messersmith, E. P. Giannelis, Chem. Mater. 1993, 5, 1064

[25] P. B. Messersmith, E. P. Giannelis, J. Polym. Sci., Part A: Polym. Chem. 1995, 33, 1047.

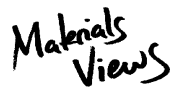

www.MaterialsViews.com
Macromol. Mater. Eng. 2011, 296, 1101-1106

(c) 2011 WILEY-VCH Verlag GmbH \& Co. KGaA, Weinheim 
[26] D. Kubies, N. Pantoustier, P. Dubois, A. Rulmont, R. Jerome, Macromolecules 2002, 35, 3318.

[27] B. Lepoittevin, N. Pantoustier, M. Devalckenaere, M. Alexandre, D. Kubies, C. Calberg, R. Jerome, P. Dubois, Macromolecules 2002, 35, 8385.

[28] P. Viville, R. Lazzaroni, E. Pollet, M. Alexandre, P. Dubois, J. Am. Chem. Soc. 2004, 126, 9007.

[29] J. B. Di, D. Y. Sogah, Macromolecules 2006, 39, 5052.

[30] M. A. Tasdelen, Eur. Polym. J. 2011, 47, 937.

[31] M. Yoonessi, H. Toghiani, W. L. Kingery, C. U. Pittman, Macromolecules 2004, 37, 2511.

[32] M. Yoonessi, H. Toghiani, T. L. Daulton, J. S. Lin, C. U. Pittman, Macromolecules 2005, 38, 818.

[33] M. Yoonessi, H. Toghiani, C. U. Pittman, J. Appl. Polym. Sci. 2006, 102, 2743.

[34] M. A. Tasdelen, W. Van Camp, E. Goethals, P. Dubois, F. Du Prez, Y. Yagci, Macromolecules 2008, 41, 6035.

[35] A. Oral, M. A. Tasdelen, A. L. Demirel, Y. Yagci, J. Polym. Sci., Part A: Polym. Chem. 2009, 47, 5328.

[36] O. Y. Zhou, X. W. Fan, C. J. Xia, J. Mays, R. Advincula, Chem. Mater. 2001, 13, 2465.

[37] X. W. Fan, O. Y. Zhou, C. J. Xia, W. Cristofoli, J. Mays, R. Advincula, Langmuir 2002, 18, 4511.

[38] M. Sangermano, G. Malucelli, E. Amerio, A. Priola, E. Billi, G. Rizza, Prog. Org. Coat. 2005, 54, 134.

[39] E. Amerio, M. Sangermano, G. Malucelli, A. Priola, B. Voit, Polymer 2005, 46, 11241.

[40] Y. Yagci, S. Jockusch, N. J. Turro, Macromolecules 2010, 43, 6245.

[41] J. M. Yeh, S. J. Liou, Y. W. Chang, J. Appl. Polym. Sci. 2004, 91, 3489.
[42] L. Keller, C. Decker, K. Zahouily, S. Benfarhi, J. M. Le Meins, J. Miehe-Brendle, Polymer 2004, 45, 7437.

[43] S. Benfarhi, C. Decker, L. Keller, K. Zahouily, Eur. Polym. J. 2004, 40, 493.

[44] C. Decker, L. Keller, K. Zahouily, S. Benfarhi, Polymer 2005, 46, 6640.

[45] R. Peila, G. Malucelli, A. Priola, J. Therm. Anal. Calorim. 2009, 97, 839.

[46] G. Malucelli, R. Bongiovanni, M. Sangermano, S. Ronchetti, A. Priola, Polymer 2007, 48, 7000 .

[47] R. Peila, G. Malucelli, M. Lazzari, A. Priola, Polym. Eng. Sci. 2010, 50, 1400

[48] G. S. Sur, H. L. Sun, S. G. Lyu, J. E. Mark, Polymer 2001, 42, 9783.

[49] J. M. Yeh, C. L. Chen, Y. C. Chen, C. Y. Ma, H. Y. Huang, Y. H. Yu, J. Appl. Polym. Sci. 2004, 92, 631.

[50] I. Mondragon, L. Solar, A. Nohales, C. I. Vallo, C. M. Gomez, Polymer 2006, 47, 3401.

[51] O. Monticelli, A. Bottino, I. Scandale, G. Capannelli, S. Russo, J. Appl. Polym. Sci. 2007, 103, 3637.

[52] P. Anadao, L. F. Sato, H. Wiebeck, F. R. Valenzuela-Diaz, Appl. Clay Sci. 2010, 48, 127.

[53] C. Dizman, S. Ates, L. Torun, Y. Yagci, Beilstein J. Org. Chem. 2010, 6, 56.

[54] P. M. Ajayan, L. S. Schadler, P. V. Braun, "Nanocomposite Science and Technology", Wiley-VCH, Weinheim 2003, p. 131.

[55] M. Alcoutlabi, G. B. McKenna, J. Phys.: Condens. Matter 2005, 17, R461.

[56] P. Rittigstein, J. M. Torkelson, J. Polym. Sci., Part B: Polym. Phys. 2006, 44, 2935.

[57] J. H. Lee, T. G. Park, H. S. Park, D. S. Lee, Y. K. Lee, S. C. Yoon, J.-D. Nam, Biomaterials 2003, 24, 2773. 